\title{
'People Consider Us Devils': Exploring Patterns of Exclusion Facing Adolescents with Disabilities in Ethiopia
}

\author{
Nicola Jones ${ }^{1}$ (D) $\cdot$ Jennifer Seager ${ }^{2} \cdot$ Workneh Yadete $^{3}$
}

Accepted: 20 February 2021

(c) The Author(s) 2021, corrected pubilcation 2021

\begin{abstract}
The 2030 Sustainable Development Goals' call to 'leave no one behind' has helped to highlight the importance of investing in inclusive services for persons with disabilities in low- and middle-income countries (LMICs). Evidence on the experiences of young Ethiopians with disabilities remains weak. Drawing on quantitative and qualitative data from 2017 to 2018, this article explores the educational, bodily integrity and psychosocial outcomes of adolescents with different impairment types (visual, hearing and physical) in rural and urban communities. Our findings indicate that young people with disabilities face intersecting barriers to inclusive education, heightened vulnerability to gender- and age-based violence, and increased psychosocial distress compared to peers without disabilities. Implications of these findings for policy and programming, include: the pressing need for specialised training and mentoring of education and other service providers; investments in support networks for parents of adolescents with disabilities; and strengthening of disability-inclusive social protection and referral mechanisms.
\end{abstract}

Keywords Ethiopia · Adolescents · Disability · Impairment type · Inclusion · Leave no one behind

\section{Résumé}

Les objectifs de développement durable de l'Agenda 2030 plaident pour « ne laisser personne de côté », et aident à souligner l'importance de l'investissement dans les

\author{
Nicola Jones \\ n.jones@odi.org.uk \\ Jennifer Seager \\ jseagermuz@email.gwu.edu \\ Workneh Yadete \\ worknehyadete@gmail.com \\ 1 Overseas Development Institute, London, UK \\ 2 George Washington University, Washington, DC, USA \\ 3 GAGE Ethiopia, Addis Ababa, Ethiopia
}

Published online: 22 March 2021 
services inclusifs pour les personnes handicapées dans les pays à faibles ou moyen indice de développement (en anglais : «Low- and middle- income countries », LMICs). Cependant, l'évidence sur le terrain des expériences des jeunes Éthiopiens handicapés reste faible. Utilisant des données quantitatives et qualitatives de 20172018, cet article explore les résultats à niveau éducationnel, d'intégrité corporelle, et psychosociale des adolescents affectés par des handicaps divers (visuels, auditifs, et physiques) dans des communautés rurales et urbaines. Nous trouvons que les jeunes handicapés font face à des barrières croisées à l'éducation inclusive ; qu'ils sont plus vulnérables à des violences sexistes et en base à leur âge ; et qu'ils ressentent plus de détresse psychosociale par rapport à leurs camarades sans handicap. Les implications de ces résultats, en termes de politiques et de programmes, sont : une nécessité urgente de formation et de mentorat des fournisseurs d'éducation et d'autres services ; l'investissement dans les réseaux de soutien des parents d'adolescents handicapés ; et le renforcement des programmes de protection sociale inclusifs des personnes handicapés et de leurs mécanismes de renvoi.

\section{Introduction}

It has become increasingly clear over the past decade that meeting international development goals will not be possible unless there is greater support for persons with disabilities to realise their human rights. An estimated $80 \%$ of persons with disabilities live in developing countries (Aguilar 2017; World Health Organization (WHO) and World Bank 2011), and there is growing evidence on the role of disability in perpetuating the cycle of exclusion and poverty (Walker 2013). People with disabilities are at greater risk of exclusion from a wide range of dimensions that support the development of human capabilities: they are more likely to experience food insecurity, more likely to lack access to safe water and sanitation, more likely to be deprived of their rights to education and healthcare, more likely to have poor housing, and to have poorer access to decent work, assets and financial services (WHO and World Bank 2011; Mitra et al. 2013).

However, while there is a general consensus that poverty and disability are closely linked, particularly where disabilities begin in childhood (Banks et al. 2017; Mont 2014), we know very little about the experiences of young people with disabilities (Groce and Kett 2014). ${ }^{1}$ The WHO and World Bank (2011) estimate that between 93 and 150 million children and adolescents under 18 years have a disability, with most living in LMICs - and that they are concentrated in the sub-Saharan Africa region. Around $17.6 \%$ of the Ethiopian population-including 2.5 million children-have at least one disability (WHO and World Bank 2011; Tadele 2019). The Ethiopian government has made multiple commitments to support the rights of persons with disabilities, including the 1995 Constitution, the ratification (in 2010) of the UN CRPD, the National Plan of Action of Persons with Disabilities (2012-2021) and more recently in line with the Sustainable Development Goals' (SDGs) call to leave

1 The authors clarify that youth refers to those aged 15-24 (Groce and Kett 2014).

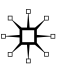


no one behind, has increased its investments in disability-responsive education services and established a dedicated department for Persons with Disabilities within the Ministry of Labour and Social Affairs. The Ministry of Education has also developed a number of policies and strategies to improve special needs and inclusive education for students with disabilities, including the Special Needs/Inclusive Education Strategy (MOE 2012) and a Master Plan for Special Needs Education/Inclusive Education in Ethiopia (2016-2025) (MOE 2016). However, the country still has a very limited evidence base to inform policy and programming on adolescents with disabilities.

Drawing on mixed-methods baseline data collected in 2017 and 2018 in Ethiopia for the Gender and Adolescence: Global Evidence (GAGE) longitudinal study, this article explores the experiences of Ethiopian adolescents (aged 10-19) with disabilities from rural and urban communities, highlighting similarities and differences in wellbeing outcomes between adolescents with different impairment types (visual, hearing, and physical). The article adopts a capabilities and intersectionality framework, focusing on adolescents with disabilities' access to education, vulnerability to gender- and age-based violence, and psychosocial wellbeing and mental health. It also explores how disability intersects with other forms of disadvantage, including gender, poverty and area of residence (remote rural locations) to shape the wellbeing and trajectories of adolescents with disabilities.

The paper is organised as follows: Section Background and Conceptual Framing provides background on the Ethiopian context and our conceptual framing; Section Methods presents the methodology, Section Findings presents our main findings, and Section Discussion presents the implications of our findings for disability-inclusive policy and programming.

\section{Background and Conceptual Framing}

\section{Defining Disability}

Disability is a heterogenous and evolving concept, encompassing people with longterm physical, mental, intellectual or sensory impairments (UN 2006). Persons with disabilities may have acquired those impairments through injury, illness or congenital conditions, and the impairments may have mild, moderate or severe impacts on a person's daily functioning, depending on the nature of the impairment as well as a range of personal (e.g. age, gender, socioeconomic status, ethnicity) and environmental (e.g. physical, social/cultural, political) factors. There is a growing consensus that understandings of disability should reflect the interaction between the individual with a health condition and contextual or environmental factors that pose significant challenges to people's enjoyment of their full human rights and potential (United Nations Convention on the Rights of Persons with Disabilities (CRPD) 2006). 


\section{Adolescents with Disabilities in LMICs}

While adolescence is increasingly recognised as an 'age of opportunity' (Sheehan et al. 2017; Steinberg 2015), whereby children's rapid maturation during the second decade of life can be capitalised upon to improve their trajectories, Maxey and Beckert (2017, p. 59) note that adolescents with disabilities are disproportionately prone to challenges. This is partly because 'societal and cultural views of disability can take on additional meaning during the adolescent years', when young people become increasingly aware of individual differences and young people with disabilities are compelled to more directly confront and balance their needs for autonomy and support. In the development literature, however, even as adolescence and disability have garnered increasing attention, adolescents with disabilities have remained largely invisible (Jones et al. 2018). Subsumed within the broader rubric of 'children with disabilities' or 'youth with disabilities', their unique age-related needs and vulnerabilities (e.g. puberty and sexuality education, growing independence, risk-taking and identity formation) have received scant attention.

This invisibility has been compounded by measurement and data collection challenges, with a dearth of robust estimates of the numbers of adolescents with disabilities in LMICs (ibid.; Groce and Kett 2014). The best approximation is based on WHO and World Bank calculations, ${ }^{2}$ which estimate that $15 \%$ of the global population-over 1 billion people, disproportionately from the bottom wealth quintile-are living with disabilities. Approximately 5\% of children and young adolescents (up to age 14) are thought to live with a moderate or severe disability (UNICEF 2013a, 2013b; WHO and World Bank 2011).

Disaggregated estimates of young people with disabilities are rare, but in line with notions of intersectionality, which highlights that some social groups are likely to face multiple and overlapping forms of disadvantage (e.g. Hooks 1981). Evidence suggests that girls are often more disadvantaged by disability due to restrictive gender norms and disability-related stigma (WHO and World Bank 2011; CRPD 2016; UNICEF 2013a, 2013b). While their access to education is catching up with that of boys with disabilities globally (Male and Wodon 2017)_-such that in some LMICs girls with disabilities are now more likely to complete primary school and less likely to be out of school at lower secondary age than boys with disabilities (UNESCO 2018) — in the poorest countries, girls with disabilities remain significantly disadvantaged compared to their male peers. Girls and women with disabilities are also more vulnerable to abuse and exploitation, and less likely to have access to good nutrition, healthcare, rehabilitation and assistive technologies (WHO and World Bank 2011).

\footnotetext{
2 These were the 2002-2004 World Health Survey from 59 countries, representing $64 \%$ of the global population, and the Global Burden of Disease study 2004 Update.
} 


\section{Vulnerability Based on Impairment Type}

The concept of disability encompasses a wide range of physical, mental, cognitive and sensory impairments (CRPD 2016), making it difficult to generalise about the experiences of persons with various disabilities. Adolescents with visual impairments, for example, and those with cognitive impairments, are both likely to face stigma and exclusion, but their day-to-day experiences and needs for care, support, services and assistive devices are likely to be very different. There has been very little research on young people with disabilities broken down by impairment type. Kuper et al. (2014), for example, note that of the countries that report to the UN Committee on CRPD implementation, very few disaggregate school enrolment figures by impairment type.

The available evidence from LMICs on impairment type and adolescent outcomes suggests that adolescents with intellectual, multiple or severe impairments are most likely to be out of school (Panda 2016; Jones et al. 2016). Not only do they require more complex adaptations to facilitate school enrolment, but they may face lower levels of parental support for education and may be deprioritised within the household for nutrition and healthcare (Jones et al. 2016, 2018). Adolescents with cognitive impairments, especially girls, appear to be at heightened risk of sexual violence (Braathen et al. 2017; Frohmader and Ortoleva 2013), while adolescents with hearing impairments appear to be the most socially isolated, as they are sometimes unable to communicate even with their own families; where they are also out of school, their social isolation can be extreme (Bhatta et al. 2018; Jones et al. 2016).

\section{A Capabilities and Intersectional Framing}

The capabilities approach was developed by Amartya Sen $(1984,2004)$ and nuanced to better capture gender dynamics by Martha Nussbaum (2011) and to explore how individual and environmental factors interact to shape the likelihood that persons with disabilities will be able to reach their full potential by Sophie Mitra (2006). It explores the assets needed (economic, human, political, emotional and social) to achieve valued ways of 'doing and being'. Importantly, the approach champions investments in people with diverse trajectories, including the most marginalised and 'hardest to reach', such as adolescents with disabilities.

In this paper we focus on three of GAGE's six capability domains because of the critical role they play in adolescent wellbeing and transitions into early adulthood (e.g. Patton et al 2018), particularly for adolescents with disabilities (e.g. Groce and Kett 2014): education and learning; psychosocial wellbeing; and bodily integrity and freedom from violence. We explore these capabilities using an intersectional lens (Crenshaw 1989) to capture the diversity of experiences of young people with disabilities in Ethiopia as they advance through adolescence, and how those experiences are shaped by gender, age, impairment type, geographical location (urban versus rural) and household economic status. 
Table 1 GAGE quantitative sample of adolescents in Ethiopia, by gender, age, and geographic location

\begin{tabular}{lccl}
\hline & Total & Without disability & With disability \\
\hline Total & 6826 & 6495 & 315 \\
Younger & 5495 & 5230 & 249 \\
(aged 10-12) & & & \\
Older (aged 15-17) & 1331 & 1265 & 66 \\
Male & 3061 & 2895 & 159 \\
Female & 3765 & 3600 & 156 \\
Rural & 4649 & 4428 & 208 \\
Urban & 2177 & 2067 & 107 \\
Disaggregated by disability type & \\
Seeing & & & 72 \\
Hearing & & 85 \\
Walking & & 126 \\
Self-care & & 50 \\
Cognition & & 81 \\
Communication & & 101 \\
\hline
\end{tabular}

Note that adolescents may have more than one disability, so the sum of the disaggregated disabilities will not equal the total number of adolescents with disabilities

\section{Methods}

\section{Data Collection and Ethics}

This article draws on baseline data (collected in 2017 and 2018) from the GAGE longitudinal mixed-methods research study using quantitative surveys and qualitative tools to explore what works to support the development of adolescents' capabilities. Quantitative surveys were conducted with more than 6,800 adolescents and their caregivers. Surveys were administered face-to-face and included the Washington Group questions which identify disability according to six core functional domains: seeing, hearing, walking, self-care, cognition, and communication.

The sample included two cohorts: younger adolescents (aged 10-12 years, in urban, rural and pastoralist areas) and older adolescents (aged 15-17 years, in urban areas only), with and without disabilities. The research sites included communities in three regions (Afar, Amhara and Oromia), and one city administration (Dire Dawa). A household census was used to identify potential respondents, and a random sample of female and male adolescents was drawn from this census for the quantitative research. Table 1 outlines the quantitative sample, by gender, age, location, and disability status and type and Table 2 presents summary statistics on the prevalence of adolescents by disability type, utilizing survey weights to make the estimates representative of Ethiopian adolescents in our study areas as a whole. Overall, 3.2 percent of adolescents in our study areas had at least one disability, with the most common disability being mobility across all age and gender cohorts and 


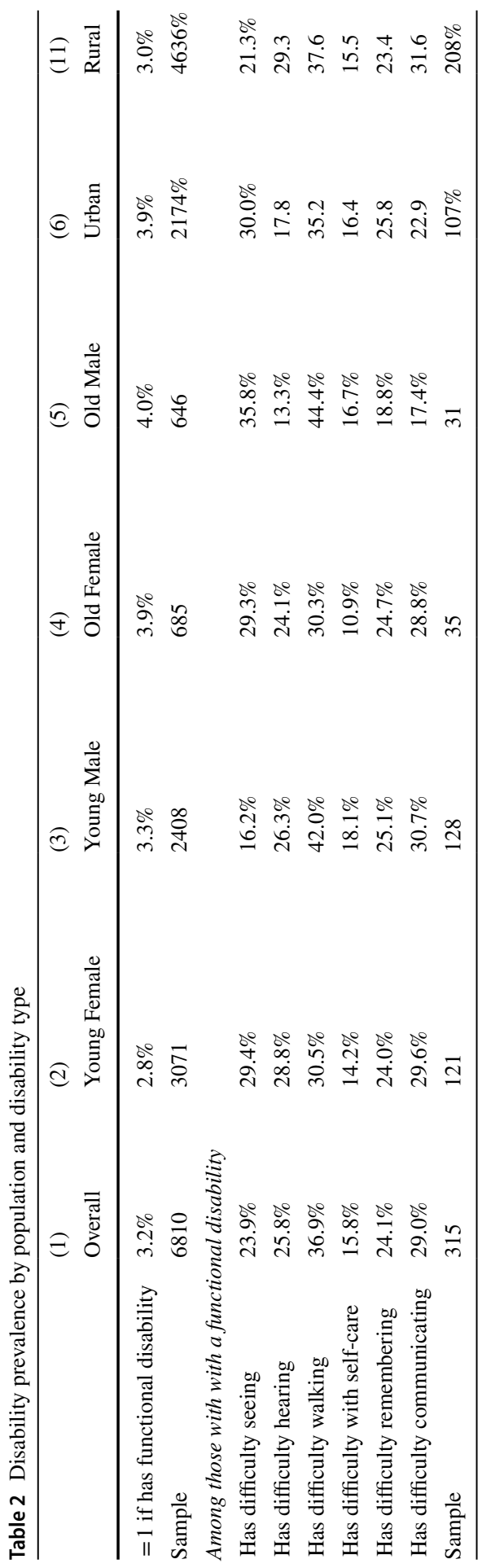




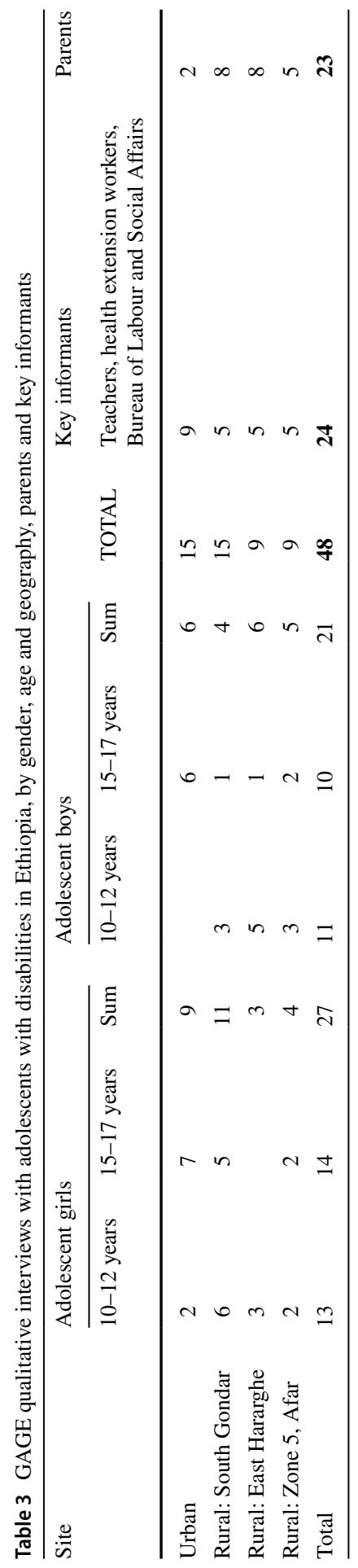

k 
locations. Disability prevalence is higher among older adolescents and among adolescents living in urban areas.

A sub-sample of 48 adolescents with disabilities from the survey were included in the qualitative research sample. Where insufficient numbers of young people with disabilities were identified through the survey in a given community, the qualitative researchers purposively sought to include adolescents with different impairment types by snowballing through schools, health extension workers and community leaders. A survey was then subsequently administered with these adolescentsaccounting for approximately half of the qualitative sample. For the qualitative sample overview, including interviews with parents and key informants, see Table 3. Qualitative tools included interactive individual and group tools, and participatory activities such as body mapping and community mapping designed to capture young people's experiences and perceptions in their own voices. We used the same qualitative tools for adolescents with disabilities as for those without disabilities to allow young people to tell their own story free of externally imposed social categories.

\section{Research Ethics}

Research ethics approvals were obtained through the Overseas Development Institute's (ODI) Research Ethics Committee, the Addis Ababa University College of Health Sciences Institutional Review Board, and the George Washington University Committee on Human Research Institutional Review Board. Researchers were trained on how to interact appropriately with adolescents, including adolescents with different types of disability. Where feasible we worked with local sign language interpreters (typically teachers) to interact with adolescents with hearing impairments, or with family members who had sometimes developed their own communication system with their adolescent. Verbal assent to participate in the research was obtained from adolescents under 18 years, and verbal consent was obtained from caregivers. Surveys were translated into Afaan Oromo, Afar Af' and Amharic, and were piloted before being undertaken across the sample. Data was generated through face-to-face interviews in people's homes with researchers from the same region and of the same sex as the adolescent.

\section{Data Analysis}

Analysis of the survey data focused on indicators for education, economic empowerment, bodily integrity, and psychosocial wellbeing. Measures included indicators of school enrolment, reasons for dropout, engagement in paid work, experience of violence from peers and adults in school and at home, experience of psychological distress, whether the adolescent speaks up in class, and has a friend they trust. Summary statistics describing these indicators are presented in the text, with differences explored across disability status using simple linear regression. All means are weighted to reflect the probability of being included 
in the study sample, and thus provide results that are representative of the study areas. Standard errors are clustered by community when testing for differences. Here we report only differences that are statistically significant at the $\mathrm{p}<0.05$ level.

For the qualitative research, preliminary analysis took place during daily and site-wide debriefings with the research team, and findings were used to develop a thematic codebook. All interviews were transcribed and translated by native speakers of the local language, then coded using MAXQDA following the GAGE ' 3 Cs' (capabilities, change strategies, and contexts) framework but with flexibility to incorporate local specificities.

The mixed-methods analysis used a sequenced approach. The qualitative team drew on the narratives generated by adolescents, their parents and key informants to nuance the quantitative findings, and the quantitative team further disaggregated the data by impairment type, gender and age, to explore emerging patterns within and across sites. This iterative process was particularly important given that the issues discussed (stigma, exclusion, and exposure to violence) were very sensitive.

\section{Findings}

Across the three capability domains investigated in this paper, adolescents with disabilities fared significantly worse than their counterparts without disabilities, although there was significant variation by impairment type, as well as by gender, geographical residence and age.

\section{Education}

Young persons with disabilities in Ethiopia are less likely to be enrolled in school, more likely to drop out early if they do enroll, and realise poorer outcomes.

\section{Enrolment Barriers}

Non-enrolment may be due to stigma (Jones et al. 2018) and to insufficient disability inclusive infrastructure at national level. Ethiopia has a limited but growing number of schools with specialist teaching for pupils with disabilities, catering to 316,271 students (Tilahun et al. 2017). ${ }^{3}$ A 2015 Ministry of Education study estimated that $27.9 \%$ of disabled people are school-aged children (Ministry of Education 2016), but the most recent enrolment figures show that only $11 \%$ of children with disabilities are enrolled in primary school and $2.85 \%$ in secondary school (Ministry of Education 2019). Table 4 shows enrolment status and educational attainment by disability

\footnotetext{
3 The 2018/2019 Ministry of Education Abstract does not provide the number of schools, only the number of students with 'special needs'.
} 


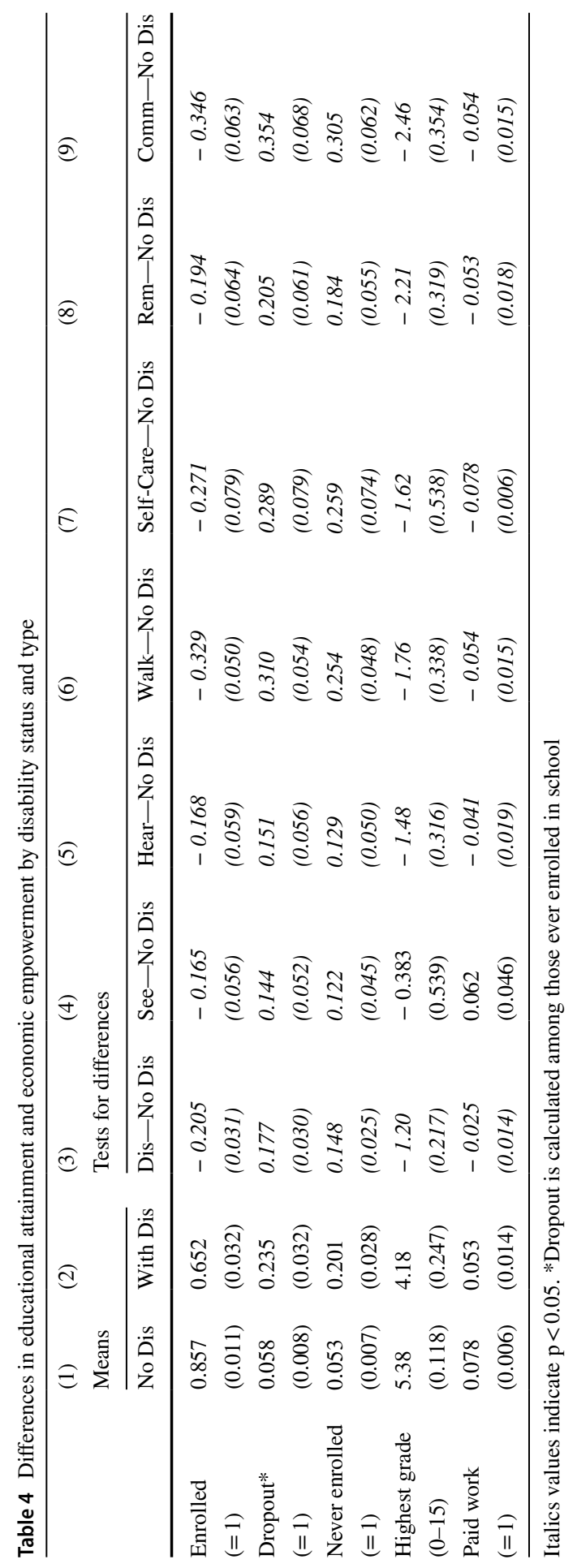


status (columns 1 and 2), the difference between adolescents with and without disabilities (column 3), and differences by disability type (columns 4-9). Of the GAGE sample, adolescents with disabilities are 20.2 percentage points less likely to be enrolled in school than those without disabilities (65.2\% and $85.4 \%$ respectively). The enrolment gap is shaped by type and severity of disability: adolescents with walking disabilities are 32.9 percentage points less likely to be enrolled than adolescents with other types of disabilities; and adolescents with communication disabilities are 34.6 percentage points less likely to be enrolled than adolescents with other disability types.

Our qualitative research identified several other key barriers to enrolment, including insufficient funding to build disability inclusive infrastructure, a lack of adequately trained specialist teachers, and a dearth of tailored learning materials. The government has initiated a teacher training programme to build skills around Braille and sign language, and is starting to scale up 'disability-friendly' schools with integrated 'resource' classrooms to provide extra help for children with visual, hearing and intellectual impairments. Such schools are now offering classes in Braille or sign language for children up to grade 4. A key informant at a school in South Gondar noted that 'students flood to our school from far distant areas'.

However, while Amhara and other regions now have dedicated 'special needs' classrooms, other regions (particularly rural communities) lack such opportunities. As a 12-year-old boy with a hearing impairment from Community $\mathrm{H}$ in East Hararghe explained, 'Because of the illness with my ears [he could not hear what was being said in school], I dropped out and started to support my father... I started to work as a daily labourer and support my family's livelihood...' An official from the Bureau of Women and Children in South Gondar noted that many schools lack funds to cater for the diverse needs of adolescents with disabilities:

There is only one primary school for special needs education. But this school does not address the needs of all children with special needs. For instance, one parent came with his blind son ...to our office and we took him to the school, but the school did not have the budget to accommodate such children... The budget is very limited and priority is given to very few children with severe disabilities.

Moreover, even when 'special needs' education facilities exist, economic barriers can hinder uptake. The survey findings suggest that adolescents with disabilities are 2.5 percentage points less likely to engage in paid work (see Table 4), although engagement in paid work is low overall (7.8\% among those without disabilities compared to $5.3 \%$ across the full sample, with the difference driven by younger adolescents), making them more dependent on their families for support. The qualitative findings also showed that adolescents with disabilities may not be prioritised within their family to attend school. In some cases (e.g. Amhara), where the regional government provides a small stipend for students attending 'special needs' classes, these barriers are partially mitigated. However, some students reported that the stipend was inadequate, especially because their families assumed it covered their educational costs, and therefore did not provide complementary support. This was particularly challenging for adolescents with hearing 
impairments, who received a lower stipend, and for adolescents with physical impairments, who received nothing. As a specialist teacher from Debre Tabor underscored:

For visually impaired students, they get 360 Ethiopian birr [ETB] [12 USD] per month plus 600 ETB [20 USD] for school uniform [annually]. For the deaf, it is 200 ETB [6.70 USD] per month and 400 ETB [13 USD] for school uniform. Because this money is not enough, many deaf students drop out of school. They want to earn money before school. So, we advise them to work in the afternoon and come to school in the morning.

Our qualitative findings highlighted that discriminatory attitudes on the part of parents, teachers and fellow students also act as a barrier. An 11-year-old girl with a hearing impairment from Community G in Amhara explained that 'People consider us devils. They [parents] don't want to let us out of the house'. Similarly, a 12-year-old boy with a hearing disability that developed in middle childhood in Community $\mathrm{H}$ in East Hararghe recalled his experience: 'They didn't realise my illness. Instead of supporting me, they were beating me with a stick as I was not able to listen and accordingly respond to their questions... When I told them I couldn't listen, they told me not to ask questions and beat me for not listening to them.' Key informants confirmed these attitudinal barriers, as one health worker from Community $\mathrm{G}$ in South Gondar explained:

Children with physical disabilities are isolated and considered as unproductive and dependent... They typically don't get married and are considered as unsuccessful in their education. The families are also not permitting [them] to go to school so they are confined to the home. As a result, they are affected psychologically and think they are not as important as people without a disability.

Students with disabilities are also more likely to face barriers in accessing technical and vocational education and training (TVET) programmes than their peers without disabilities due to lack of resources and support (Cocks and Thoreson 2013). Most vocational instructors in Ethiopia are not informed about national or international policies or legal instruments designed to include persons with disabilities, though according to one study, most students with disabilities in TVET programmes identified soft skills and affirmative action initiatives as key entry points into the workforce (Malle et al. 2015). This finding was confirmed by the qualitative interviews, which highlighted that discrimination and costs were major barriers in accessing TVET. We did, however, find several cases of young people with disabilities who had negotiated with local community members to take on informal apprenticeships (e.g. in bakeries and as basket-weavers). 


\section{Dropout Risks}

The risk of dropout among adolescents with disabilities is high—at nearly 5 times the rate of adolescents without disabilities (23.5\% compared to 5.8\%). They are also less likely to ever attend school in the first place (20\% compared to $5.3 \%$ ) (see Table 4). The main reasons for dropout related to the adolescent's illness or disability (49\%), as well as illness or disability of another household member (22\%). Other reasons cited in the survey include stigma or discrimination at school, parents not wanting them to continue attending, books or other supplies being too expensive, and lack of food (highlighting the role of poverty in limiting access). Reasons identified in the qualitative interviews add nuance to the quantitative survey findings; students highlighted that peers were sometimes forced to drop out after grade 4 (when adolescents with disabilities are integrated into mainstream classes) as the disability stipend (except in Amhara) is only for attending 'special needs' classes.

The risk of dropout after grade 4 was especially high for students with hearing impairments, as some teachers in inclusive classroom settings were reported to not make efforts to communicate lessons in a way that facilitated lip-reading. By contrast, students with visual impairments were able to use hand-held recorders to record the lessons and listen back at home or with friends.

Adolescents with visual and mobility impairments complained about inaccessible school facilities, especially toilets and libraries. As a 16-year-old female student with a visual impairment from Batu noted: 'I have never used the library here, because I need to come back again [from my regular class] to use the library and I get tired [navigating the school grounds] so I can't come.' Another 16-year-old female student in Batu, also with a visual impairment, emphasised that toilets were not accessible for students in a wheelchair: 'I don't need anything but for the others who use a wheelchair, the toilet facility must be improved'. This compounds the challenges that adolescent girls already reported facing on account of limited menstrual hygiene facilities, especially in rural schools.

\section{Academic Attainment Challenges}

Our survey found that adolescents with disabilities have poorer learning outcomes than their peers without disabilities, with boys particularly disadvantaged compared to girls. On average, adolescents with disabilities have attained 1.2 fewer years of education than adolescents without disabilities (4.2 years compared to 5.4 years respectively). Attainment is particularly low among adolescents with walking disabilities (1.8 years behind adolescents without disabilities), remembering disabilities (2.2 years behind) and communication disabilities (2.5 years behind), echoing average enrolment.

The qualitative interviews revealed that adolescents with disabilities are more likely to be over-age for grade. As a teacher from Community E in South Gondar explained:

We have never received a student [with disabilities] who is in the appropriate grade for age-all of them are over-age. Many of them are above 15 . There 
are also first graders who are 20 years old. This year we were able to enrol younger students of age 10 and above... When you get older, you might not be sharp in learning like younger children... their performance can be affected.

This disadvantage is often compounded by the fact that 'special needs' classes often include students with a range of impairments but inadequate resources and materials to support their diverse needs. As a specialist teacher in Debre Tabor explained:

I have a total of 21 students: 3 students are blind, 15 are deaf and 3 have cognitive impairments... all are below grade 2 because the sign language teaching started only two years back... it is difficult to manage all in one class because they have different needs and problems.

Low attainment is also partly attributable to the fact that many teachers are reluctant to integrate children with disabilities into mainstream classrooms after 'special needs' classes end at grade 4. Temesgen (2019) found that in Amhara, 70\% of teachers surveyed had negative attitudes toward integration. Even when primary teachers' attitudes toward inclusion are generally positive, they are thwarted by a lack of resources, training and inclusive programming (Asres 2019). As a specialist educationalist in Dire Dawa noted, specialist training is rare and not adequately tailored:

For visual disabilities, Braille is very important; for a person who doesn't hear, sign language is important. People with autism problems need different and basic support. There should be a professional who teaches them how to eat, dress, behave... There are many schools which purport to teach students with disabilities but when it comes to quality, they are dead.

Specialist teachers also noted that a lack of parental support—and even neglect—contributed to poor attainment. In some cases adolescents with disabilities were at greater risk of hunger due to poverty and neglect, which compounded their learning difficulties. As a teacher in Batu explained:

Some of our students come to school hungry... For example, one student in my class, her mother does not have a job and the father has married another wife and often abuses the family... There is no school feeding programme for them. We try to comfort these students tactfully... We also know those children whose parents are very poor and come to school not eating. So there is a tearoom in this school, we bring them tea from there... from our own pocket.

\section{Bodily Integrity and Freedom from Violence}

Global evidence suggests that adolescents with disabilities, whether in school or not, are at greater risk of violence and threats to bodily integrity. They are more likely to be subject to neglect and abuse in their homes and in society more broadly (Jones et al. 2019), and are more likely to experience physical and emotional violence than their non-disabled peers (Jones et al. 2012), often perpetrated by family members and peers (African Child Policy Forum (ACPF) 2010). 


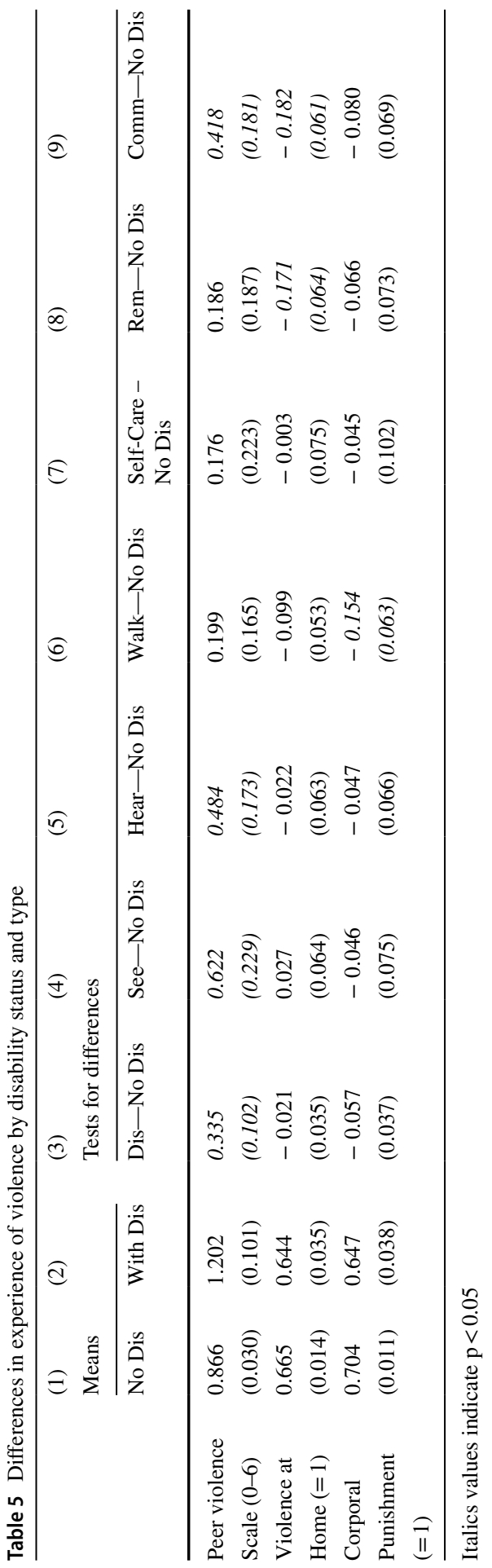


Overall, our quantitative evidence points to higher rates of peer violence toward adolescents with disabilities but suggests less violence from adults (see Table 5). On average, adolescents with disabilities have experienced $39 \%$ more peer violence than those without; adolescents with visual, hearing, and communication disabilities experience the most peer violence. This finding was reinforced by the qualitative data. A 10-year-old boy from Zone 5 (Afar) with a visual impairment described his experience:

They [the other children] insult me, calling me 'blind boy!' They warn me, saying that they will beat me when they get me alone... They have beaten me several times with sticks and stones. They beat me without any reason.

An 11-year-old girl from Community E, Amhara, who is deaf, explained through her mother that 'I refuse to do the herding with the other children. They insult me, call me names. Sometimes they beat me too.'

While the quantitative data suggests no difference between adolescents with disabilities and those without in experience of violence at home or corporal punishment, there is variation according to disability type. Adolescents with walking difficulty, remembering impairments and communication impairments are respectively $9.9(\mathrm{p}<0.1), 17.1$, and 18.2 percentage points less likely to experience violence at home. Likewise, adolescents with walking disabilities are 15.4 percentage points less likely to experience corporal punishment.

However, the qualitative findings suggest that young people with disabilities are vulnerable to violence from adults at home and at school; this perhaps reflects that more in-depth conversations facilitated through qualitative tools are needed before adolescents with disabilities feel confident to reveal experiences of corporal punishment. In particular, younger adolescents with disabilities highlighted that parental corporal punishment was not uncommon, and that they were punished for 'mistakes' (for instance, with herding and domestic chores). An 11-year-old boy with a visual impairment from Community I, Oromia, noted that his parents beat him with a stick 'when we play with water during the rainy season, when chickens enter into the house and eat food, when goats get into the house and steal food'. Other adolescents reported being punished because of poor performance at school or in Koran lessons, or for retaliating against children who insult them. As a 12-year-old girl with a physical disability from Community D, Amhara, explained: 'I get beaten with a stick when I do something wrong-for example, if I hit someone back they will beat me because they don't want to fall out with the child's parents.'

Findings about corporal punishment were mixed, with some respondents claiming that adolescents with disabilities were less likely to be subject to teacher violence and that some teachers intervened to protect students with disabilities from peer bullying, especially in schools with dedicated 'special needs' classes. For example, a 17-year-old girl with a physical disability from Debre Tabor noted, 'Teachers don't insult disabled persons. They have to treat them equally...' However, others from rural schools without 'special needs' teachers reported that they had experienced both psychological and physical violence by teachers. For example, an 11-year-old boy from Community J, Oromia, explained: 
There are good teachers and also bad teachers who can't understand our problems. For example, if I am absent for some reason, they might insult me. They call me 'blind one', which is distressing. There is no beating inside the class but outside the classroom there is beating.

A 17-year-old adolescent boy with a visual disability from Ebenat, Amhara, said:

My homeroom teacher is cruel to me. He marks me down in exams intentionally. He also prevents me from entering the class when I arrive late, but he allows others to enter even if they come to school after me. He is doing this in retaliation because I complained to the school administration that he was discriminating [against] me in the classroom.

Girls with disabilities are especially vulnerable to sex- and gender-based violence and harassment. They are often reliant on their abusers for shelter and support, and perpetrators view them as less likely to resist or report abuse (Dessie et al. 2019; ACPF 2010; WHO and World Bank 2011). Our qualitative data echoed these findings. Girls attending 'special needs' classes in Debre Tabor emphasised that they discussed problems of sexual harassment and sexual assault with their classmates. A 17-year-old girl with a physical disability explained:

Males sometimes call our mobiles [after getting our number from friends] and insulting us and trying to force us to contact them. They are male gangsters who live in town and sometimes wait in the street and grab your hand and when you strike at them to get away, they snatch and hit you. I've also experienced this.

Another 17-year-old girl with a hearing impairment confided that she had survived attempted rape while travelling between her rural village and school:

I went home to fetch my education certificate ahead of the grade 5 exams, but three gangsters beat me and two others captured my little brother-he's 12and then they beat me and tried to rape me. I was struggling and they kept beating me... luckily passers-by approached, they heard the voices, and they left me.

A 16-year-old adolescent boy with a physical disability from Batu, Oromia, confirmed such reports:

There are also people who act as brokers who bring female children [with disabilities] from rural areas by convincing parents that they will get a job and send money back home. But they are exposed to sexual abuse and harassment.

\section{Psychosocial Wellbeing}

Evidence on the psychosocial wellbeing of adolescents with disabilities is extremely limited, though some research suggests that they have far fewer opportunities to socialise than their non-disabled peers (Jones et al. 2018). Table 6 presents summary statistics and differences in adolescents' experiences of psychological distress 


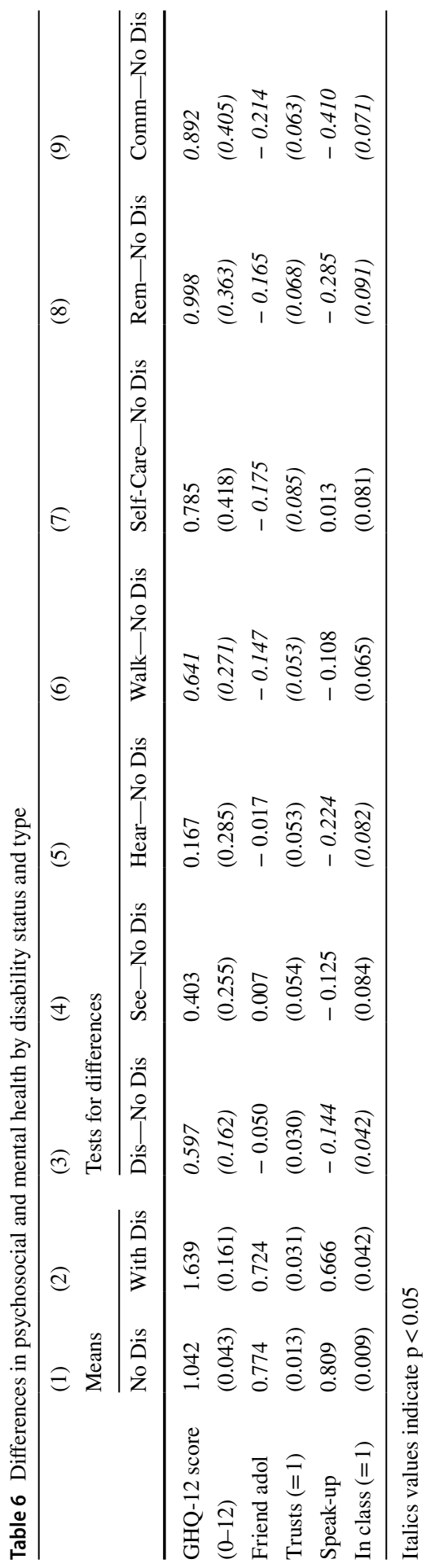


and their degree of social connectedness with peers. On an internationally validated scale of vulnerability to psychological distress, adolescents with disabilities report a 0.6 higher General Health Questionnaire (GHQ-12) score than adolescents without disabilities (see Table 6). Higher psychological distress is common across all adolescents with disabilities, except for those with visual and hearing disabilities.

The qualitative findings resonated strongly with the survey data on this point, but did not identify strong differences based on impairment type. Some young people explained their psychological distress in terms of limited independence. A 17-yearold girl with a physical impairment from Debre Tabor summed up her feelings as follows:

I am psychologically depressed because I think I am inferior to my peers and that I lack something... It's not because of the discrimination that I face from the community. But, by myself, there are things that I can't do. For example, I need to go to the flour mill to be independent and carry the flour and I can't do that.

Others expressed sadness at being unable to join in activities as equals and to support their families in line with generational and gender norms. For example, a 17-year-old boy with a physical disability from Debre Tabor explained:

I can't perform part-time jobs located far from this area like most of my friends do.... I felt very sad because I was unable to go to other villages like my friends and sell cattle to cover my educational expenses... I couldn't support my family and it sometimes makes me sad.

In terms of social connectedness with peers, the quantitative survey found no difference between adolescents with disabilities and their non-disabled peers in the likelihood of having a friend the adolescent trusts. However, when the data is disaggregated by disability type, adolescents with walking, remembering, communication, and self-care difficulties are between 15 and 22 percentage points less likely to have a friend they trust. The survey findings also indicate that adolescents with disabilities are 14.4 percentage points less likely to speak up in class than adolescents without disabilities (66\% and $81 \%$ respectively). This probably reflects higher levels of mental distress, fewer peer networks (among some disability types), and greater vulnerability to peer violence and bullying (as already discussed). The disparity is largest for adolescents with communication difficulties, who are 41 percentage points less likely to speak up in class. Adolescents with remembering impairments and hearing impairments also fare relatively worse, being 28.5 and 22.4 percentage points less likely to speak up in class.

The qualitative data also paint a mixed picture. Adolescents in school highlighted that peer networks there helped to mitigate their risks of psychosocial distress (some talked about attending school for the first time as a transformational experience for their psychosocial wellbeing). An 18-year-old girl from Ebenat, who is blind, explained:

I thought I was dead, but not anymore. After I started school here, I now believe I can be just like any other person. After I saw how blind people man- 
age their lives, I started having hope again. My friends became the source of my hope.

However, others-especially those with visual and hearing disabilities, emphasised their social isolation. As a 17-year-old girl with a hearing impairment from Batu explained:

Since no one listens to me, I do not have someone to share issues with. Only my parents understand me a little but no one else around here does.

A 16-year-old boy with a visual impairment from Debre Tabor underscored his general sense of futility about the future, given the dearth of social support:

I could not be successful in my life because of my disability... It is impossible and creates a lot of mental stress. For instance, when my friends enjoy and do whatever they like, I find myself alone and that disturbs my mind so much.

Moreover, some adolescents noted that they lacked confidence to use guidance and counselling services available in some urban schools, as a 17-year-old girl with a physical disability from Debre Tabor explained: 'I am shy and I am not comfortable using those services.'

\section{Discussion}

Our findings show that young persons with disabilities in Ethiopia face significant educational and employment disadvantages. They are less likely to be enrolled in school, more likely to drop out early if they do enroll, and to have lower attainment. Parental and community attitudes and stigmatization, inadequate and underresourced inclusive education facilities, very limited specialist teachers, physical and emotional violence on the part of peers and teachers, and inadequate social assistance together contribute to these inequitable educational outcomes. Young people with walking and communication impairments were found to be most at risk. For older adolescents, poorer educational outcomes and community stigmatization contribute to lower employment opportunities. Our findings also indicate that young people with disabilities face intersecting barriers to inclusive education, especially girls who reported often facing discrimination on account of their disability and gender, and rural adolescents where disability infrastructure is especially lacking.

We find that outcomes vary considerably among young people with different types of disabilities, partly due to uneven access to tailored support and services. In particular, adolescents with mobility, self-care, and communication disabilities fare worst in terms of access to education and paid work and are also more likely to exhibit psychological distress and less likely to have a friend that they trust, indicating that current accommodations in education and work environments are insufficient to meet their needs. While adolescents with visual and hearing disabilities are more likely to be enrolled in school than their peers with other disability types, they 
are more likely to face violence from their peers, indicating that greater support is needed for these students within communities and schools.

In terms of vulnerability to violence, our findings indicated that young people with disabilities face higher rates of peer violence than adolescents without disabilities, especially those with visual, hearing and communication disabilities. Our results around violence from parents and teachers painted a more mixed picture-the survey findings suggested that young people are less likely to experience violence from adults, whereas our qualitative findings found that adolescents with disabilities were still at risk of such violence, but that they were more reluctant to report it, possibly due to heightened dependence on caregivers and less confidence in reporting violence and abuse. Girls with disabilities also reported that they faced significant risks of sexual harassment and assault in the community.

Young people with disabilities were also found to suffer significantly higher rates of mental distress and adolescents with walking, remembering, communication and self-care difficulties faced lower levels of social connectedness with peers. Adolescents with disabilities were also less confident than peers without disabilities in speaking up in class.

\section{Conclusions}

The implications of our findings about the complex, intersecting barriers that adolescents with disabilities face suggest that there is a pressing case for policy and programmatic action to invest in inclusive services and infrastructure to better support adolescents with disabilities_and capitalise on the window of opportunity adolescence presents-in line with SDG commitments to leave no one behind. Our research suggests that adolescents with disabilities urgently need an integrated package of tailored support to help address intersecting forms of disadvantage and set them on a better trajectory for a fulfilled and empowered adulthood. This would need to include better-resourced classrooms to support the acquisition of braille or sign language skills as well as subsequent integration into inclusive education settings that cater to the specific needs of adolescents with varying impairment types, as well as assistive devices and adequately trained teachers to deliver inclusive education (both specialist and general teachers), in line with the Ministry of Education's multi-year 'Special Needs'/Inclusive Education Plan. ${ }^{4}$ Such efforts would need to be accompanied by more substantial and better-targeted social assistance programmes to overcome the financial vulnerabilities that our findings highlighted as precluding access to services for many adolescents with disabilities and their families. In light of the greater vulnerability of adolescents with disabilities to peer violence, and of girls' greater risk of gender-based violence, social assistance could helpfully be linked to complementary services, including violence prevention and response involving police and the courts.

\footnotetext{
4 This should be in line with the commitments made by the Ministry of Education (2016)'s Master Plan for Special Needs Education/Inclusive Education in Ethiopia 2016-2025.
} 
Given that stigma and discrimination at household and community levels emerged as another key constraint to adolescents' capabilities, efforts are urgently needed to engage and support caregivers of adolescents with disabilities, who are often themselves stigmatised and excluded. Likewise, it is important to ensure that all caregivers have access to tailored information, guidance and support networks, including for psycho-emotional support and respite care.

To reduce community-level stigma and ensure that adolescents with disabilities are not deprioritised within the household, there is an urgent need for investments in awareness-raising with parents, communities and service providers about the causes of disability, the rights of people with disabilities, and the importance of supporting young people with disabilities to aspire to — and work towards — an independent future.

\section{Compliance with ethical standards}

Conflict of interest On behalf of all authors, the corresponding author states that there is no conflict of interest.

Open Access This article is licensed under a Creative Commons Attribution 4.0 International License, which permits use, sharing, adaptation, distribution and reproduction in any medium or format, as long as you give appropriate credit to the original author(s) and the source, provide a link to the Creative Commons licence, and indicate if changes were made. The images or other third party material in this article are included in the article's Creative Commons licence, unless indicated otherwise in a credit line to the material. If material is not included in the article's Creative Commons licence and your intended use is not permitted by statutory regulation or exceeds the permitted use, you will need to obtain permission directly from the copyright holder. To view a copy of this licence, visit http://creativecommons.org/licen ses/by/4.0/.

\section{References}

African Child Policy Forum (ACPF). 2010. Breaking the Silence, Violence Against Children with Disabilities in Africa. Addis Ababa: The African Child Policy Forum.

Aguilar, C.D. 2017. Social protection and persons with disabilities. International Social Security Review 70 (4): 45-65.

Asres, G. 2019. Teachers' attitude towards the inclusion of students with disabilities in the regular classroom: The case of selected primary schools in South Gondar administrative towns-Ethiopia. Journal of Education and Training Studies. https://doi.org/10.11114/jets.v7i12.4636.

Banks, L.M., H. Kuper, and S. Polack. 2017. Poverty and disability in low- and middle-income countries: A systematic review. PLOS ONE 12 (12): e0189996. https://doi.org/10.1371/journal.pone.0189996.

Bhatta, C.R., S. Bhujel, S. Dhakal, N. Gyawali, M.K. Shah, S. Shrestha, A. Sigdel, M. Sunar, S. Bernays, S. Hameed, S. Kayastha, P. Lamsal, M. Panthee, and M. Zuurmond. 2018. Strengthening the Voices of Adolescents with Disabilities in Nepal. London: International Centre for Evidence at the London School of Hygiene \& Tropical Medicine, CBM Nepal and Plan International Nepal.

Braathen, S.H., P. Rohleder, and G. Azalde. 2017. Sexual and Reproductive Health and Rights of Girls with Disabilities: A Review of the Literature. London: University of East London and SINTEF.

Cocks, E., and S.H. Thoresen. 2013. Barriers and Facilitators Affecting Course Completions by Apprentices and Trainees with Disabilities. National Vocational Education and Training Research (NCVER) Programme. Adelaide, Australia. https://www.ncsehe.edu.au/publications/barriers-affec ting-course-completions-by-apprentices-with-disabilities. 
United Nations Convention on the Rights of Persons with Disabilities (CRPD). 2016. https://www.un.org/ development/desa/disabilities/convention-on-the-rights-of-persons-with-disabilities.html.

Crenshaw, K. 1989. Demarginalising the intersection of race and sex: A black feminist critique of antidiscrimination doctrine, feminist theory and anti-racist politics. University of Chicago Legal Forum 139: 139-167.

Dessie, S., Y. Bekele, and M. Bilgeri. 2019. Sexual violence against girls and young women with disabilities in Ethiopia. Including a capability perspective. Journal of Global Ethics 15 (3): 325-343. https://doi.org/10.1080/17449626.2019.1690554.

Frohmader, C., and S. Ortoleva. 2013. The Sexual and Reproductive Rights of Women and Girls with Disabilities. Issue Paper. ICPD Beyond 2014-International Conference on Human Rights.

Groce, N.E., and M. Kett. 2014. Youth with Disabilities. Working Paper Series: No. 23. Leonard Cheshire Disability and Inclusive Development Centre, University College London.

Hooks, Bell. 1981. Ain't I a Woman. Boston, MA: South End Press.

Jones, L., M.A. Bellis, S. Wood, K. Hughes, E. McCoy, L. Eckley, G. Bates, C. Mikton, T. Shakespeare, and A. Officer. 2012. Prevalence and risk of violence against children with disabilities: A systematic review and meta-analysis of observational studies. Lancet 380 (9845): 899-907.

Jones, N., B. Abu Hamad, K. Odeh, P. Pereznieto, O. Abu Al Ghaib, G. Plank, E. Presler-Marshall, and M. Shaheen. 2016. Every Child Counts: Understanding the Needs and Perspectives of Children with Disabilities in the State of Palestine. London and Jerusalem: ODI and UNICEF.

Jones, N., E. Presler-Marshall, and M. Stavropoulou. 2018. Adolescents with Disabilities: Enhancing Resilience in Delivering Inclusive Development. London: Gender and Adolescence: Global Evidence.

Jones, N., E. Presler-Marshall, S. Baird, J. Hicks, G. Emirie, W. Yadete, Y. Alemayehu, B. Bekele, and E.K. Woldevesus. 2019. Adolescent Bodily Integrity and Freedom from Violence in Ethiopia. London: Gender and Adolescence: Global Evidence.

Male, C., and Q. Wodon. 2017. Disability Gaps in Educational Attainment and Literacy, The Price of Exclusion: Disability and Education Notes Series. Washington DC: The World Bank.

Malle, A., R. Pirttimaa, and T. Saloviita. 2015. Inclusion of students with disabilities in formal vocational education programs in Ethiopia. International Journal of Special Education 30 (2): 57-67.

Maxey, M., and T. Beckert. 2017. Adolescents with disabilities. Adolescent Research Review 2: 59-75.

Ministry of Education. 2019. Education Statistics Annual Abstract 2018/19. Addis Ababa: Federal Democratic Republic of Ethiopia.

Mitra, S. 2006. The capability approach and disability. Journal of Disability Policy Studies 16 (4): 236247. https://doi.org/10.2139/ssrn.2330438.

Mitra, S., A. Posarac, and B. Vick. 2013. Disability and poverty in developing countries: A multidimensional study. World Development 41: 1-18.

MoE (Ministry of Education). 2016. A master plan for special needs education/inclusive education in Ethiopia 2016-2025. Addis Ababa: Government of Ethiopia.

Mont, D. 2014. Childhood Disability and Poverty. Working Paper Series No. 25. London: Leonard Cheshire Disability and Inclusive Development Centre, University College London.

Panda, R.K. 2016. Socially Exclusion and Inequality: Opportunities in Agenda 2030. New Delhi: WNTA, GCAP SETF/NACDOR, CES, World Vision, Welthungerhilfe and GCAP.

Patton, G.C., C.A. Olsson, V. Skirbekk, R. Saffery, M.E. Wlodek, P.S. Azzopardi, M. Stonawski, B. Rasmussen, E. Spry, K. Francis, Z.A. Bhutta, N.J. Kassebaum, A.H. Mokdad, C. Murray, A.M. Prentice, N. Reavley, P. Sheehan, K. Sweeny, R.M. Viner, and S.M. Sawyer. 2018. Adolescence and the next generation. Nature 554 (7693): 458-466. https://doi.org/10.1038/nature25759.

Sheehan, P., K. Sweeny, B. Rasmussen, A. Wils, H. Friedman, J. Mahon, G. Patton, S. Sawyer, E. Howard, J. Symons, K. Stenberg, S. Chalasani, N. Maharaj, N. Reavley, H. Shi, M. Fridman, A. Welsh, E. Nsofor, and L. Laski. 2017. Building the foundations for sustainable development: A case for global investment in the capabilities of adolescents. The Lancet 390 (10104): 1792-1806.

Steinberg, L. 2015. Age of Opportunity: Lessons from the New Science of Adolescence. New York: Eamon Dolan/Mariner Books.

Tadele, F. 2019. Towards a more inclusive economic growth and social development in Ethiopia: The state of vulnerable social groups and social protection. In Challenges and Opportunities for Inclusive Development in Ethiopia. Proceedings of Conference Held in 2017, ed. D. Rahmato and M. Ayenew. Forum for Social Studies: Addis Ababa.

Temesgen, Z. 2019. Teacher's attitude toward inclusion of children with disabilities into their classrooms of Amhara regional state of Ethiopia. Studies in Special Education 1 (8): 9-21. 
Tilahun, D., A. Fekadu, B. Tekola, M. Araya, I. Roth, B. Davey, C. Hanlon, and R. Hoekstra. 2017. 'Ethiopian community health workers' beliefs and attitudes towards children with autism: impact of a brief training intervention' OnlineFirst: https://doi.org/https://doi.org/10.1177/1362361317730298

Tirfessa, K., C. Lund, G. Medhin, Y. Hailemichael, A. Fekadu, and C. Hanlon. 2019. Food insecurity among people with severe mental disorder in a rural Ethiopian setting: A comparative, populationbased study. Epidemiology and Psychiatric Sciences 28 (4): 397-407. https://doi.org/10.1017/S2045 796017000701.

UN. 2006. United Nations Convention on the Rights of Persons with Disabilities. $6^{\text {th }}$ December 2006. https://www.un.org/disabilities/documents/convention/convention_accessible_pdf.pdf. Accessed 23 June 2020.

United Nations Department of Economic and Social Affairs (UNDESA). 2018. Disability and Development Report: Realizing the Sustainable Development Goals by, for and with Persons with Disabilities. New York: United Nations.

United Nations Economic, Social and Cultural Organisation (UNESCO). 2018. Education and disability: Analysis of data from 49 countries. Montreal: UNESCO Institute for Statistics. http://uis.unesco. org/en/news/education-and-disability-analysis-data-49-countries. Accessed 23 June 2020.

UNICEF. 2013a. State of the World's Children 2013: Children with Disabilities. New York: UNICEF.

UNICEF. 2013b. Children and Young People with Disabilities. Fact Sheet. New York: UNICEF.

Walker, R. 2013. Poverty in Global Perspective: Is Shame a Common Denominator? Journal of Social Policy 42 (2): 215-233.

World Health Organization (WHO) and World Bank. 2011. World Report on Disability. Geneva: WHO.

Publisher's Note Springer Nature remains neutral with regard to jurisdictional claims in published maps and institutional affiliations. 